\title{
PERILAKU ASERTIF DALAM MENINGKATKAN PRESTASI KERJA KONSULTAN MULTI LEVEL MARKETING
}

\section{ASSERTIVENESS IN IMPROVING WORK PERFORMANCE OF MULTI-LEVEL MARKETING CONSULTANT}

\author{
Tri Widyastuti ${ }^{1)}$ Bisri $^{2)}$ Suhardi $^{3)}$ \\ ${ }^{1}$ Fakultas Ekonomi dan Bisnis, Universitas Bina Sarana Informatika \\ ${ }^{2,3}$ Fakultas Teknik dan Informatika, Universitas Bina Sarana Informatika \\ ${ }^{1}$ Email: tri.twt@bsi.ac.id
}

\begin{abstract}
ABSTRAK
Perilaku asertif mendorong individu untuk berperilaku terpuji dalam berinteraksi dengan individu lainnya. Perilaku tegas, jujur dan saling menghargai dapat meningkatkan sikap toleransi dan terbuka dalam penyampaian informasi. Perilaku ini menciptakan suasana yang harmonis dan nyaman sehingga dapat memacu peningkatan prestasi kinerja konsultan Multi Level Marketing (MLM). Penelitian ini menggunakan metode deskriptif kuantitatif dengan populasi penelitian sebanyak 125 orang konsultan MLM. Data diambil berdasarkan kuesioner mengenai perilaku assertiveness dan prestasi kerja konsultan MLM. Berdasarkan hasil uji regresi linier sederhana didapatkan hasil bahwa asertif berpengaruh secara positif dan signifikan terhadap prestasi kerja konsultan MLM.
\end{abstract}

Kata Kunci : Perilaku Asertif, Prestasi Kerja, Multi Level Marketing

\section{ABSTRACT}

Assertiveness encourages individuals to behave well in interacting with other individuals. Decisive, honest and respectful behavior can increase tolerance and openness in the delivery of information. This behavior creates a harmonious and comfortable atmosphere so that it can spur increased work performance achievements of Multi-Level Marketing (MLM) consultants. This study uses a quantitative descriptive method with a population of 125 MLM consultants. Data was taken based on a questionnaire regarding the behavior of assertiveness and work performance of MLM consultants. Based on the results of a simple linear regression test, the results show that assertiveness has a positive and significant effect on MLM consultant work performance.

Keywords: Assertiveness, Work Performance, Multi Level Marketing 
P-ISSN 2580 - 7781

E-ISSN 2615 - 3238

\section{PENDAHULUAN}

Kinerja atau prestasi kerja merupakan pencapaian hasil kerja oleh seseorang yang merupakan cerminan hasil yang dicapai oleh seseorang atau sekelompok orang, yang bisa diukur berdasarkan standar (V. \& B. Rivai, 2005). Kinerja merupakan suatu acuan keberhasilan seorang karyawan dalam melakukan pekerjaan sesuai fungsinya dengan target dan standar yang berlaku selama periode khusus. Kinerja keseluruhan pada pekerjaan adalah sama dengan jumlah atau ratarata kinerja pada fungsi pekerjaan yang penting. Fungsi yang berkaitan dengan pekerjaan tersebut akan dilakukan dan tidak dilakukan dengan karakteristik kinerja individu. (Sunarto, 2003) menyatakan kinerja yang tinggi dapat tercapai oleh karena kepercayaan (trust) timbal balik yang tinggi di antara anggotaanggotanya artinya para anggota mempercayai integritas, karakteristik, dan kemampuan setiap anggota lain.

Menurut (V. \& B. Rivai, 2005) Kinerja atau prestasi kerja merupakan hasil atau tingkat keberhasilan seeorang secara keseluruhan selama periode tertentu di dalam melaksanakan pekerjaan atau tugas sebanding dengan berbagai kemungkinan seperti standar hasil kerja, target atau sasaran kriteria yang telah ditentukan terlebih dahulu dan disepakati bersama. (Wirawan, 2009) menjelaskan lebih lanjut bahwa kinerja adalah singkatan dari kinetika energy kerja yang dalam padanan bahasa Inggris diartikan sebagai performance, yaitu keluaran yang dihasilkan oleh fungsi-fungsi atau indikator-indikator suatu pekerjaan atau profesi dalam waktu tertentu. Berdasarkan pengertian diatas dapat disimpulkan bahwa kinerja atau prestasi kerja adalah tingkat keberhasilan seseorang atau karyawan baik secara kuantitas maupun kualitas yang dicapai berdasarkan target atau tujuan yang telah ditetapkan selama satu periode yang telah ditentukan sebelumnya.

Pencapaian kinerja didasarkan atas kriteria atau standar kinerja, yaitu tingkat kinerja yang ditentukan dalam sebuah organisasi atau perusahaan. Standar kinerja harus realistis, dapat diukur dan mudah dipahami agar bermanfaat bagi seluruh pihak, baik karyawan maupun perusahaan. (Wilson, 2012) menjelaskan standar kinerja sebagai tingkat yang diharapkan dalam pekerjaan tertentu untuk dapat diselesaikan, dan merupakan pembanding atas tujuan atau target yang ingin 
P-ISSN 2580 - 7781

E-ISSN 2615 - 3238

dicapai. Menurut (Abdullah, 2014) Standar kinerja memiliki beberapa fungi, yaitu:

1. Sebagai tolok ukur memperhitungkan keberhasilan dan ketidakberhasilan kinerja ternilai.

2. Memotivasi karyawan agar bekerja lebih keras untuk mencapai target sesuai standar kinerja sebagai alat memotivasi karyawan dikaitkan dengan imbalan dalam system kompensasi.

3. Memberikan arah pelaksanaan pekerjaan yang harus dicapai baik secara kualitatif maupun kuantitatif.

4. Memberikan pedoman pada karyawan berkaitan dengan proses pelaksanaan pekerjaan untuk mencapai standar pekerjaan yang telah ditetapkan.

Adapun persyaratan standar kinerja (Abdullah, 2014) adalah:

1. Terdapat hubungan yang relevan dengan strategi organisasi.

2. Mencerminkan keseluruhan tanggung jawab karyawan dalam melaksanakan pekerjaannya.

3. Memperhatikan pengaruh faktor-faktor diluar control karyawan.

4. Memperhatikan teknologi dan proses produksi.

5. Sensitif, dapat membedakan antara kinerja yang dapat diterima dan yang akan diterima.

6. Memberikan tantangan kepada karyawan.

7. Realistis, dapat dicapai oleh karyawan.

8. Berhubungan dengan waktu pencapaian standar.

9. Dapat diukur dan ada alat ukur untuk mengukur pencapaian standar.

10. Standar harus konsisten.

11. Standar harus adil.

12. Standar harus memenuhi ketentuan undang-undang dan peraturan ketenagakerjaan.

Menurut (Siagian, 2008) berdasarkan kegunaannya penilaian kinerja memiliki dua peran, yaitu bagi individu, berperan sebagai umpan balik tentang berbagai hal seperti kemampuan, kelebihan, dan kekurangan yang pada gilirannya 
P-ISSN 2580 - 7781

E-ISSN 2615 - 3238

bermanfaat untuk menentukan tujuan, jalur, rencana dan pengembangan karirnya; dan bagi organisasi, berperan sebagai pengambil keputusan tentang berbagai hal seperti identifikasi kebutuhan program pendidikan dan pelatihan, rekrutmen, seleksi, program pengenalan, penempatan, promosi, sistem balas jasa, serta berbagai aspek lain dalam proses manajemen SDM. Selanjutnya, (Henry, 2015) menegaskan penilaian kinerja sebagai proses dimana organisasi mengevaluasi pelaksanaan kinerja individu untuk memperbaiki keputusan personalia dan memberikan umpan balik kepada karyawan tentang pelaksanaan kerja mereka serta memungkinkan perusahaan untuk mengetahui seberapa baik karyawan itu bekerja jika dibandingkan dengan standar organisasi.

Indikator penilaian kinerja secara individu (Robin S.P, 2006) adalah sebagai berikut:

1. Kualitas kerja diukur dari persepsi karyawan terhadap kualitas pekerjaan yang dihasilkan serta kesempurnaan tugas terhadap keterampilan dan kemampuan karyawan.

2. Kuantitas merupakan jumlah yang dihasilkan dinyatakan dalam istilah seperti jumlah unit, jumlah siklus aktivitas yang diselesaikan.

3. Ketepatan Waktu merupakan tingkat aktivitas diselesaikan pada awal waktu yang dinyatakan, dilihat dari sudut koordinasi dengan hasil output serta memaksimalkan waktu yang tersedia untuk aktivitas lain.

4. Efektivitas merupakan tingkat penggunaan sumber daya organisasi (tenaga, uang, teknologi, bahan baku) dimaksimalkan dengan maksud menaikkan hasil dari setiap unit dalam penggunaan sumber daya.

5. Kemandirian merupakan tingkat seseorang karyawan yang nantinya akan dapat menjalankan tugas kerjanya.

6. Komitmen kerja merupakan suatu tingkat dimana karyawan mempunyai komitme kerja dengan instansi dan tanggung jawab karyawan terhadap kantor. 
P-ISSN 2580 - 7781

E-ISSN 2615 - 3238

(Gomes, 2010) mendeskripsikan lebih terinci indikator penilaian kinerja yaitu:

1. Quantity of work

a. Jumlah kerja yang dilakukan

b. Jumlah kerja yang dicapai dalam satu periode tertentu

2. Quality of work

a. Keterampilan dalam melaksanakan tugas

b. Kualitas yang dicapai berdasarkan persyaratan, kesesuaian dan kesiapan

3. Job knowledge

a. Luasnya pengetahuan mengenai pekerjaan

b. Luasnya pengetahuan mengenai keterampilan

4. Creativeness

a. Keahlian gagasan

b. Kemampuan menyelesaikan persoalan

5. Cooperativeness

a. Kesediaan kerjasama dengan atasan

b. Kesediaan kerjasama dengan bawahan

6. Depentability

a. Kesadaran dalam hal kehadiran

b. Dapat dipercaya dalam hal kehadiran

\section{Initiative}

a. Semangat dalam melaksanakan tugas

b. Semangat mengerjakan tanggungjawabnya

8. Personal Qualities
a. Kepemimpinan
b. Integritas pribadi

Dalam melaksanakan pekerjaan, setiap karyawan pasti melakukan interaksi dengan karyawan lainnya melalui komunikasi, baik verbal maupun non verbal. Penyampaian komunikasi yang dilakukan karyawan akan berhasil jika orang lain bersedia mengikuti dan mendengarkan beberapa informasi yang disampaikan. 
P-ISSN $2580-7781$

E-ISSN 2615 - 3238

Tetapi seringkali terjadi perbedaan persepsi yang dapat disebabkan karena kurang jelasnya informasi dan kurangnya komunikasi, sehingga dapat terjadi kesalahpahaman persepsi. Oleh karena itu diperlukan sebuah bentuk pendekatan yang efektif untuk dapat mengubah atau menyesuaikan persepsi seseorang terhadap orang lain dan informasi baru yang didapatnya.

Assertiveness merupakan pendekatan interpersonal yang mengedepankan pada perilaku jujur dalam mengekspresikan perasaan dan keinginan seseorang. Rimm dan Masters (Rakos, 1991) menyatakan bahwa perilaku asertif adalah suatu perilaku dalam hubungan interpersonal yang bersifat jujur serta mengekspresikan pikiran dan perasaan secara langsung dengan tetap memperhitungkan kondisi sosial yang ada. Kemampuan asertif mengedepankan kemampuan untuk mendengar perspektif orang lain dan mengekspresikan dirinya dengan jujur dan penuh rasa hormat meliputi pernyataan atau ide-ide secara jelas dan dengan penuh rasa percaya diri, tanpa merasa bersalah. Seseorang dengan perilaku asertif lebih melihat kedalam pribadi setiap individu dan bertanggung jawab terhadap apa yang dipikirkan, dilakukan, dan lain-lain, serta jujur dalam menyajikan pesan verbal dan non verbal secara konsisten.

Assertiveness describes as a form of communication in which needs or wishes are stated clearly with respect of oneself and the other person in the communication (Simpson, The Styles, Models \& Philosophy of Leadership). Komunikasi asertif merupakan bentuk komunikasi yang mengedepankan penghargaan terhadap keinginan ataupun kebutuhan dari orang lain. Melalui komunikasi asertif setiap individu akan berusaha untuk melakukan komunikasi secara terbuka dan meminimalisir kesalahpahaman dengan mengekspresikan keinginan secara proposional tanpa menimbulkan prasangka negatif yang berakibat merugikan orang lain. Lebih lanjut (Irsyadi, 2009) menegaskan asertivitas adalah suatu kemampuan untuk mengkomunikasikan apa yang diinginkan, dirasakan, dan dipikirkan kepada orang lain namun dengan tetap menjaga dan menghargai hak-hak serta perasaan pihak lain. Menjadi asertif bukanlah hal yang mudah. Seseorang dituntut untuk jujur terhadap diri sendiri. Jujur pula dalam mengekspresikan perasaan, pendapat dan kebutuhan secara 
P-ISSN 2580 - 7781

E-ISSN 2615 - 3238

proposional, tanpa ada maksud untuk memanipulasi, memanfaatkan ataupun merugikan pihak lainnya.

Menurut (Garner, 2012), manfaat berperilaku asertif dalam komunikasi adalah menghilangkan rasa takut dan kecemasan, memberikan pengawasan pribadi dalam bertindak dan melihat secara personal bagaimana orang lain bersikap terhadap orang lain, dan meningkatkan kepercayaan diri dan penghargaan terhadap orang lain. Individu yang berperilaku asertif lebih mengutamakan pemecahan masalah dengan win-win solution, tidak memandang rendah orang lain, tidak merasa cemas dan selalu berusaha mengembangkan potensi diri secara maksimal.

Lebih lanjut (Garner, 2012) mengungkapkan ada 6 tehnik dalam komunikasi asertif:

1. Mendengar: seorang assertive harus mendengarkan apa yang dibicarakan agar mengerti dan memahami akar permasalahan yang terjadi

2. Menyatakan harapan dengan jelas: seorang assertive harus mengatakan apa yang diinginkan dengan lugas, jujur dan jelas agar dapat dipahami pihak lain

3. Memperhatikan: seorang assertive selalu berusaha memberi perhatian dan focus pada hal-hal yang terjadi dan masalah yang ada

4. Kompromi dan negosiasi: seorang assertive berusaha untuk melakuan kompromi dan negosiasi dalam menyelesaikan masalah dan mengambil keputusan

5. Bersikap gigih (persistent) dan sabar: seorang assertive tetap bersikap memegang pendirian dan sabar dalam situasi dan kondisi apapun

6. Memberikan kritik yang efektif dan membangun seorang assertive selalu memberikan masukan dan tanggapan atau kritikan positif yang membangun untuk memecahkan masalah atau konflik.

(Irsyadi, 2009) berpendapat bahwa dengan berkomunikasi asertif setiap individu makin mudah membina hubungan kerja yang komunikatif dan kondusif, Melalui kemampuan strategis dalam berkomunikasi dengan lawan bicara dan kemampuan menangani konflik yang mungkin timbul, seorang asertif akan melihat masalah dari dua arah secara bijaksana sehingga akan meningkatkan 
moral kerja, kinerja, produktivitas kita, dan membentuk kerja sama tim yang solid dalam organisasi. Oleh sebab itu seorang individu dapat menerapkan pengetahuan dan keinginan untuk target pencapaian kinerja yang maksimal.

Menurut Kotler dan Armstrong dalam (Weningtyas, 2012) menyimpulkan teknik berinteraksi dengan orang lain dan kemampuan dalam persepsi sosial sangat dibutuhkan untuk meningkatkan kinerja karyawan. Dengan penerapan perilaku asertif, seorang pekerja dapat meningkatkan kualitas kinerja karyawan karena mereka mampu menciptakan sikap keterbukaan dan rasa empati untuk membuat suasana yang lebih nyaman dan harmonis, sehingga dapat meningkatkan kenyamanan dalam melakukan pekerjaan yang dapat memacu peningkatan kinerja. Penelitian membuktikan bahwa komunikasi asertif dapat menurunkan konflik interpersonal karyawan dan memberikan pengaruh yang signifikan terhadap peningkatan kinerja (Honeya, Allfar, 2012).

Multi level marketing (MLM) merupakan sebuah jaringan kerja pemasaran yang di dalamnya terdapat sejumlah orang yang melakukan pekerjaan pemasaran produk atau jasa. MLM adalah sistem penjualan yang memanfaatkan konsumen baik sebagai tenaga penyalur secara langsung maupun sebagai konsumen dengan menggunakan beberapa level di dalam system pemasarannya. (V. Rivai, 2012) Perusahaan MLM telah memberikan banyak peluang dan manfaat bagi masyarakat, terutama ibu rumah tangga dalam meningkatkan penghasilan dan mengatasi masalah keuangan serta pengangguran. Mekanisme pemasaran dalam bisnis jaringan memberikan sistem kompensasi yang membuat para pelaku MLM atau disebut konsultan mendapatkan keuntungan yang signifikan.

Seorang konsultan MLM akan membangun jaringan pemasaran untuk menyalurkan produk atau jasa perusahaan secara berkesinambungan. Pemasaran yang dilakukan secara berjenjang ini didasarkan pada pengalaman dalam penggunaan produk/jasa tersebut dan membagikan manfaat produk/jasa tersebut kepada orang lain atau calon konsultan baru melalui berbagai media. Oleh karena itu pendekatan interpersonal melalui perilaku asertif perlu diterapkan dan menjadi modal dalam mengembangkan produktifitas dan meningkatkan kinerja para konsultan MLM. Melalui perilaku asertif, para konsultan MLM dapat membangun 
hubungan interpersonal yang baik dengan calon konsumen, mendalami karakter mereka dan memahami penyampaian mengenai produk/jasa MLM tersebut dengan lebih lugas; sehingga kemungkinan calon konsumen untuk menggunakan produk/jasa itu dan bergabung dengan MLM tersebut lebih terbuka.

\section{METODE PENELITIAN}

Berdasarkan latar belakang mengenai prestasi kerja dan kemampuan komunikasi asertif, rumusan masalah mengenai pengaruh komunikasi asertif dalam meningkatkan prestasi kerja serta teori yang mendukung penelitian, maka peneliti merumuskan hipotesis sebagai berikut: Terdapat pengaruh signifikan dan positif antara komunikasi asertif dan prestasi kerja.

Metode yang digunakan dalam penelitian ini adalah metode survey dengan pendekatan kuantitatif dengan teknik deskriptif kausalitas. Pengambilan sampel menggunakan metode random sampling terhadap konsultan Multi Level Marketing di Jakarta dan Tangerang. Data yang digunakan diambil dari hasil kuesioner mengenai komunikasi asertif dan prestasi kerja atau kinerja para konsultan MLM tersebut. Model empiris berupa analisis regresi sederhana dilakukan untuk mengetahui pengaruh dari seperangkat variabel independen terhadap variabel dependen dengan pendekatan SPSS.

Populasi penelitian adalah semua konsultan multi level marketing yang ada di Jakarta, dengan pengambilan sampel berjumlah 125 orang konsultan. Non Probability Sampling, yaitu dengan metode Convenience Sampling (Teknik penarikan sampel secara mudah (Arikunto, 2000). Dalam teknik ini peneliti menentukan responden sebagai sampel sesuai dengan kemudahan peneliti dalam mencari responden. Data yang dikumpulkan dalam penelitian ini dengan data primer yang diperoleh dengan cara menyebarkan kuesioner kepada responden.

\section{HASIL PENELITIAN DAN PEMBAHASAN}

Dari data 125 responden yang telah mengisi kuesioner diuji validitas dan reliabilitas kuesioner tersebut yang menghasilkan bahwa seluruh butir-butir pertanyaan dinyatakan valid dan reliable untuk dijadikan instrument penelitian. 
P-ISSN 2580 - 7781

E-ISSN 2615 - 3238

Adapun hasil uji validitas dan reliabilitas yang diukur dengan nilai korelasi dan Cronbach alpha dapat dilihat pada table 1 hasil uji validitas di bawah ini

Tabel 1 Uji validitas

\begin{tabular}{|c|c|c|c|c|}
\hline $\begin{array}{l}\text { No. Butir } \\
\text { Pernyataan }\end{array}$ & $\begin{array}{c}\text { Koefisien } \\
\text { Korelasi }\end{array}$ & Keterangan & Cronbach $\alpha$ & Keterangan \\
\hline \multicolumn{5}{|c|}{ Pernyataan Asertif $(\mathbf{X})$} \\
\hline $\mathbf{1}$ & $\mathbf{0 , 7 9 5 7}$ & Valid & .946 & Reliabel \\
\hline 2 & $\mathbf{0 , 7 6 8 6}$ & Valid & .946 & Reliabel \\
\hline 3 & $\mathbf{0 , 7 3 3 6}$ & Valid & .947 & Reliabel \\
\hline 4 & $\mathbf{0 , 7 1 6 7}$ & Valid & .947 & Reliabel \\
\hline 5 & $\mathbf{0 , 8 4 7 0}$ & Valid & .945 & Reliabel \\
\hline 6 & 0,7248 & Valid & .946 & Reliabel \\
\hline 7 & $\mathbf{0 , 7 2 3 9}$ & Valid & .947 & Reliabel \\
\hline 8 & 0,7049 & Valid & .947 & Reliabel \\
\hline 9 & 0,6608 & Valid & .948 & Reliabel \\
\hline 10 & $\mathbf{0 , 7 2 7 4}$ & Valid & .946 & Reliabel \\
\hline 11 & $\mathbf{0 , 7 3 8 2}$ & Valid & .946 & Reliabel \\
\hline 12 & $\mathbf{0 , 7 4 3 6}$ & Valid & .947 & Reliabel \\
\hline \multicolumn{5}{|c|}{ Pernyataan Prestasi Kerja (Y) } \\
\hline 1 & 0,6393 & Valid & .948 & Reliabel \\
\hline 2 & 0,6148 & Valid & .948 & Reliabel \\
\hline 3 & 0,7464 & Valid & .946 & Reliabel \\
\hline 4 & 0,5684 & Valid & .948 & Reliabel \\
\hline 5 & 0,6682 & Valid & .947 & Reliabel \\
\hline 6 & 0,6447 & Valid & .947 & Reliabel \\
\hline 7 & 0,6110 & Valid & .948 & Reliabel \\
\hline 8 & 0,6129 & Valid & .948 & Reliabel \\
\hline 9 & 0,6177 & Valid & .947 & Reliabel \\
\hline 10 & 0,6895 & Valid & .947 & Reliabel \\
\hline 11 & 0,6232 & Valid & .947 & Reliabel \\
\hline 12 & 0,6863 & Valid & .947 & Reliabel \\
\hline
\end{tabular}


P-ISSN 2580 - 7781

E-ISSN 2615 - 3238

\begin{tabular}{|c|c|c|c|c|}
\hline 13 & $\mathbf{0 , 5 4 9 8}$ & Valid & .948 & Reliabel \\
\hline 14 & $\mathbf{0 , 6 8 5 6}$ & Valid & .947 & Reliabel \\
\hline 15 & $\mathbf{0 , 6 7 4 2}$ & Valid & .947 & Reliabel \\
\hline 16 & $\mathbf{0 , 6 5 3 0}$ & Valid & .948 & Reliabel \\
\hline
\end{tabular}

Setelah dilakukan uji pendahuluan untuk memastikan model regresi yang digunakan memang tepat dan memenuhi persaratan model uji secara statistic yaitu, pertama dilakukan uji normalitas data dengan menggunakan uji satu sampel Kolmogorov-smirnov yang hasilnya dapat dilihat pada table 2 di bawah ini:

Tabel 2. Hasil Uji Satu Sampel Kolmogorov-Smirnov

One-Sample Kolmogorov-Smirnov Test

\begin{tabular}{|c|c|c|}
\hline & & $\begin{array}{c}\text { Unstandardized } \\
\text { Residual }\end{array}$ \\
\hline \multicolumn{2}{|l|}{$\mathrm{N}$} & 125 \\
\hline \multirow[t]{2}{*}{ Normal Parameters ${ }^{\mathrm{a}, \mathrm{b}}$} & Mean & .0000000 \\
\hline & $\begin{array}{l}\text { Std. } \\
\text { Deviation }\end{array}$ & 4.99099342 \\
\hline \multirow{3}{*}{$\begin{array}{l}\text { Most Extreme } \\
\text { Differences }\end{array}$} & Absolute & .083 \\
\hline & Positive & .039 \\
\hline & Negative & -.083 \\
\hline \multicolumn{2}{|l|}{ Kolmogorov-Smirnov Z } & .924 \\
\hline \multicolumn{2}{|l|}{ Asymp. Sig. (2-tailed) } & .360 \\
\hline
\end{tabular}

Dari table di atas di dapatkan nilai sig. yang sebesar 0,360 yang berarti lebih besar dari alpha 0,05 sehingga dapat diambil kesimpulan bahwa data pada penelitian ini berdistribusi normal. Kemudian selanjutnya dilakukan uji autokorelasi dengan durbin Watson sebesar 1,844 yang nilai tersebut lebih besar dari pada du yang sebesar 1,7241 dan lebih kecil dari 4-du yang berarti dapat diambil kesimpulan bahwa model regresi ini terbebas dari autokorelasi.

Selanjutnya kita akan melihat hasil uji F yaitu untuk melihat seberapa bagus model dalam penelitian ini untuk memprediksi kinerja. Dari hasil uji F dapat dilihat bahwa F sig yang sebesar 0,000 pada table 3 di bawah ini; 
Tabel 3 ANOVA

\begin{tabular}{|l|r|r|r|}
\hline Model & \multicolumn{1}{|c|}{ Df } & F & Sig. \\
\hline $1 \quad$ Regression & 1 & 223.438 & $.000^{\mathrm{a}}$ \\
$\quad$ Residual & 123 & & \\
$\quad$ Total & 124 & & \\
\hline
\end{tabular}

Hasil tersebut menunjukan bahwa model ini mampu menerangkan tingkat kinerja.

Selanjutnya pada table 4. Model summary di bawah ini dapat dilihat koefesien determinan sebesar $64,5 \%$.

Tabel 4. Model Summary

\begin{tabular}{|l|r|r|r|}
\hline Model & \multicolumn{1}{|c|}{ R } & R Square & Durbin-Watson \\
\hline 1 & $.803^{\mathrm{a}}$ & .645 & 1.844 \\
\hline
\end{tabular}

Dari hasil tersebut dapat dikatakan bahwa variable penjelas pada model penelitian dapat menerangkan variable terikat dengan cukup besar yaitu sebesar 64,5\% sedangkan sisanya sebesar 35,5\% diterangkan oleh variable lain diluar model ini.

Nilai koefisien asertif sebesar 0,904 dengan nilai konstanta sebesar 24,970; dapat menunjukkan bahwa hasil perhitungan tersebut didapatkan persamaan :

$$
\mathrm{Y}=24,970+0,904 \mathrm{X}
$$

Hal ini dapat dikatakan bahwa perilaku asertif berpengaruh secara signifikan dan positif atau searah sehingga perubahan prestasi kerja bersifat searah dengan perubahan asertif. Hal ini sejalan dengan yang dikatakan oleh Irsyad bahwa asertif itu berguna dalam hal menjalin komunikasi dengan baik. Sehingga dengan komunikasi yang baik itulah konsultan MLM dapat menyampaikan maksud dan tujuannya dengan jelas sehingga dapat dimengerti oleh orang yang diajak berkomunkasi. Dengan terjalinnya komunikasi yang baik antara konsultan MLM dengan orang lain tentu saja hal ini dapat meningkatkan prestasi kerja konsultan MLM.

\section{KESIMPULAN}

Dari hasil pembahasan tersebut di atas dapat diambil kesimpulan bahwa asertif ternyata secara signifikan dan positif mempengaruhi prestasi konsultan MLM. Mengedepankan perilaku asertif dapat membuat para konsultan MLM untuk dapat berkomunikasi dengan baik, terhadap upline, downline, bahkan 
terhadap calon downline (anggota baru). Selain itu, berperilaku asertfi juga bisa meningkatkan hubungan yang lebih kekeluargaan dengan saling menghormati dan menghargai pendapat dan opini orang lain, sehingga dapat meminimalisir konflik yang kemungkinan timbul. Hal ini tentu saja merupakan hal yang positif bagi para konsultan MLM untuk dapat meningkatkan prestasi kerja mereka dengan mempelajari berperilaku asertif dan mengaplikasikannya dalam melakukan pekerjaan mereka. Perusahaan MLM bisa membuat sebuah program pelatihan meningkatkan perilaku asertif para konsultannya agar dapat meningkatkan kinerja mereka, menambah konsultan baru, dan meningkatkan omset perusahaan.

\section{DAFTAR PUSTAKA}

Abdullah, M. (2014). Manajemen dan Evaluasi Kinerja Karyawan. Yogyakarta: Penerbit Aswaja Pressindo.

Arikunto. (2000). Prosedur Penelitian Suatu Pendekatan Praktek. Jakarta: Rineka Cipta.

Garner, E. (2012). Assertiveness: Reclaim your assertive birthright. Denmark: Ventus Publishing APs.

Gomes, F. C. (2010). Manajemen Sumber Daya Manusia. Yogyakarta: ANDI Yogyakarta.

Henry, Si. (2015). Manajemen Sumber Daya Manusia (Edisi Keti). Yogyakarta: STIE YPKN.

Honeya, Allfar, Y. A. and R. P. G. (2012). Pengaruh Pelatihan Komunikasi Asertif pada Perawat Pelaksana yang Mengalami Konflik Interpersonal terhadap Kinerjanya dalam Memberikan Asuhan Keperawatan di Ruang Rawat Inap RSUD Solok. Jurnal Keperawatan, 8(2), 147-153.

Irsyadi, A. R. (2009). Meningkatkan Komunikasi Asertif. GEMA Jamsostek Media Internal, 2(Edisi 6), 12-13.

Rakos, R. F. (1991). Assertive Behavior: Theory, Research and Training. International Series on Communication. London: Routledge.

Rivai, V. (2012). Islamic Marketing: membangun dan Mengembangkan Bisnis dengan Praktik Marketing Rasululah SAW. Jakarta: Gramedia.

Rivai, V. \& B. (2005). Performance Appraisal: Sistem yang tepat untuk Menilai Kinerja Karyawan dan Meningkatkan Daya Saing Perusahan. In Jakarta: PT. RajaGrafindo Persada.

Robin S.P. (2006). Perilaku Organisasi (Edisi 10). Jakarta: PT. Indeks Kelompok Gramedia.

Siagian, S. (2008). Manajemen Sumber Daya Manusia. Jakarta: Binapura Aksara. Sunarto. (2003). Pengertian Kinerja Karyawan. Jakarta: Penerbit Gramedia.

Weningtyas, E. D. M. N. S. (2012). Pengaruh Komunikasi Interpersonal dan Kualitas Pelayanan terhadap Kepuasan Konsumen. Jurnal Psikologika, $17(1)$. 
P-ISSN $2580-7781$

E-ISSN 2615 - 3238

Wilson, B. (2012). Manajemen Sumber Daya Manusia. Bandung: PT. Erlangga.

Wirawan. (2009). Evaluasi Kinerja Sumber Daya Manusia: Teori Aplikasi dan Penelitian. Jakarta: Salemba Empat. 